\title{
Braking Characteristics of the Specified Modern Electric Vehicle During Intensive Braking
}

\author{
Eduard Kolla', Ján Ondruš² ${ }^{*}$, Marián Gogola², Željko Šarić \\ 1 University of Zilina, Institute of Forensic Research and Education, Ulica 1. mája 32, 01001 Zilina, Slovakia \\ 2 University of Zilina, Faculty of Operation and Economics of Transport and Communications, Univerzitná 1, \\ 01026 Zilina, Slovakia \\ 3 University of Zagreb, Department of Traffic Accidents Expertise, Borongajska 83a, 10 000, Zagreb, Croatia \\ * Corresponding author's e-mail: jan.ondrus@fpedas.uniza.sk
}

\begin{abstract}
The correct information, including the full braking deceleration of a vehicle, is an essential factor of the road accident process analysis. The aim of the paper was to define and compare the braking properties of the tested Tesla model S electric vehicle by means of the XL MeterTM Pro decelograph and a smartphone as a new alternative method. The measured procedure was the intensive vehicle braking by means of a fully pressed-down operation brake from the different initial velocities. Altogether, 32 measurements were carried out, out of which 16 on the dry surface and 16 on the wet surface. This paper contains the methodology and the results of the performed measurements. The data obtained by an XL Meter TM Pro measuring device were processed by means of the XL Visionä and PC Crash 11.0. software, whereas the data from the smartphone was analysed using the Diagram software. The results and data processed herewith can be useful for the forensic practice.
\end{abstract}

Keywords: electric vehicle, braking, full braking deceleration, braking distance, smartphone, application, XL MeterTM Pro, dry, wet.

\section{INTRODUCTION}

A mobility trend in the upcoming years is clear. Each major carmaker is presenting its new models in the area of electromobility. By 2020, up to 103 models of e-cars are expected to be driving on the roads [15].

With each new model, the range is extended. For example, one of the most preferred models, Nissan Leaf, has already reached a range of 350 kilometres in the new version. Tesla, full with innovations, pushes the limit of range to $600 \mathrm{ki}-$ lometres [19]. When it is considered that up to $70 \%$ of drives in Europe are below 40 kilometres per day, the electromobility is a solution not only within the urban mobility, but also at the regional and national levels [2].

The driving trend with producing zero local emission is most evident in the west European countries [14], but the absolute leader is Norway, where every third car sold in 2019 is purely electric (BEV - Battery Electric Vehicle) or a plug-in hybrid (PHEV - plug-in hybrid electric vehicle). The fastest growing countries are Germany, England and France [2, 14].

The brake system fundamentally affects the level of vehicle active safety [4]. The design and technical condition of the brake system, together with tyres [1] and other factors, such as the road surface and the slope $[3,6]$, influence the directional stability of a vehicle during the braking, and the braking distance length [3]. The braking distance represents the distance which is travelled by a vehicle from the moment of pressing the brake pedal till the vehicle stops, or till the moment when the driver stops applying the brake pedal $[3,5]$.

The full braking deceleration value during intensive braking belongs to the important input data of the traffic accident analysis [8]. Only a 


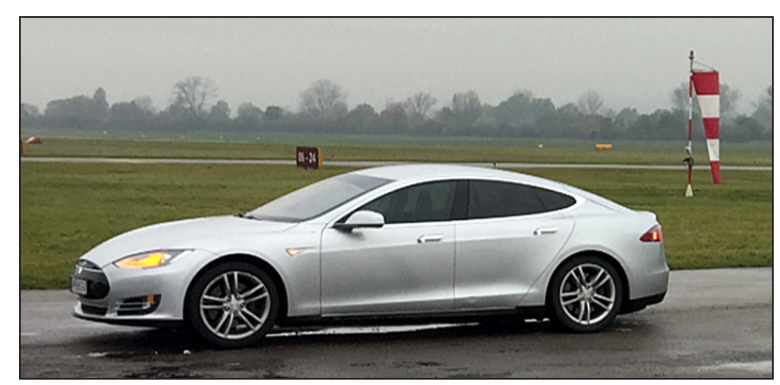

Fig. 1. The Tesla model S 60D electric testing vehicle

small number of measurements made with the electric vehicles on common roads has been published in the relevant literature [9]. This paper presents the results of measurements (specifically the full braking deceleration of the electric vehicle) and compares the different ways of measuring the braking deceleration, mostly with regards to the minimal cost of the measurement.

\section{CHARACTERISTICS OF THE ELECTRIC TESTING VEHICLE}

A Tesla model S 60D electric passenger car, production year $08 / 2013$, was used for the measurement as a testing vehicle (see fig. 1). During the trials, the electric vehicle was loaded with one person, i.e. a driver.

Tesla Model $\mathrm{S}$ is a luxurious limousine with the liftback body style. The automobile industry launched the selected model S in 2008 and its prototype was introduced by the Tesla company in 2009. In 2012 it was introduced to the international market and in the same year, the first ten models of this car were produced [10, 19]. This electromobile is powered solely by the threephase electric motor with AC current. The output of the electric motor is defined by the output of the accumulator, i.e., its capacity, depending on the size of the accumulator. This might be one of the following versions: $60,75,90$ or $100 \mathrm{kWh}$. The output of this electromobile ranks between 285 to $568 \mathrm{~kW}$ and torque from 430 to $931 \mathrm{Nm}$. Acceleration from 0 to $100 \mathrm{~km} / \mathrm{h}$ in the weakest version of battery is 5.8 seconds, and in the most powerful version -2.4 seconds $[2,19]$.

The GOODYEAR Efficientgrip tyres had the size of 245/45 R19 $102 \mathrm{~V}$. The front tyres tread depth was $4.1 \mathrm{~mm}$ and the rear tyres tread depth was $4.3 \mathrm{~mm}$ (see fig. 2). At the time of the measurement, the tyres were inflated to reach the

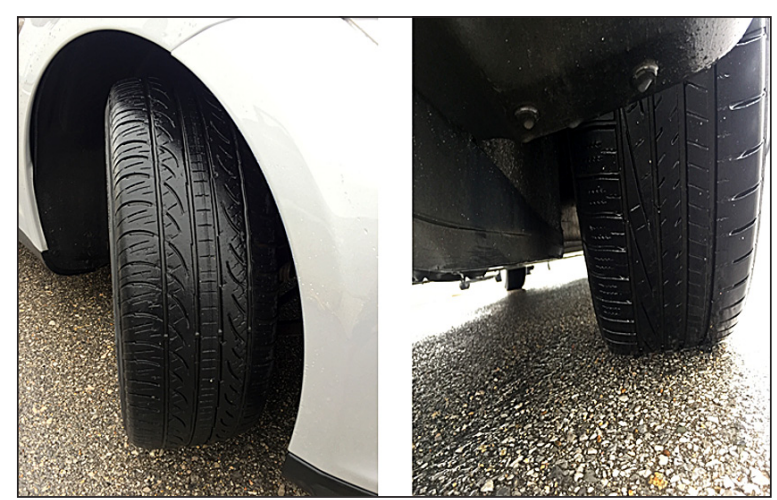

Fig. 2. Testing vehicle tyres detail

compression specified by the producer. The testing electric vehicle and its braking system were technically correct.

The active elements installed are the antilocking braking system (ABS), electric stability program (ESP), eight airbags, automatic emergency braking system, lane keep assist, lane departure warning system, blind spot detection system, traction control system and adaptive light control [19]. The technical specifications of the Tesla $\mathrm{S}$ 60D electric testing vehicle are shown in Tab. 1.

Table 1. Technical specifications of the selected Tesla model S 60D electric vehicle [19]

\begin{tabular}{|c|c|}
\hline Model & S 60D \\
\hline Body style & Liftback \\
\hline Model year & 2013 \\
\hline Battery pack capacity [kWh] & 60 \\
\hline $\begin{array}{l}\text { Max. charging } \\
\text { power AC [kW] }\end{array}$ & 22 \\
\hline $\begin{array}{l}\text { Max. charging } \\
\text { power DC [kW] }\end{array}$ & 105 \\
\hline Range [km] & 390 \\
\hline Max. power [kW] & 285 \\
\hline Max. torque $[\mathrm{Nm}]$ & 430 \\
\hline Mass weight $[\mathrm{kg}]$ & 2255 \\
\hline Dimensions $(\mathrm{L} \times \mathrm{W} \times \mathrm{H})[\mathrm{mm}]$ & $4971 \times 1963 \times 1445$ \\
\hline Wheelbase [mm] & 2959 \\
\hline Fuel type & Electricity \\
\hline Drive wheel & All wheel drive $(4 \times 4)$ \\
\hline Transmission & Automatic \\
\hline Front brakes & $\begin{array}{l}\text { Ventilated discs with the } \\
\text { diameter of } 355[\mathrm{~mm}]\end{array}$ \\
\hline Rear brakes & $\begin{array}{l}\text { Ventilated discs with the } \\
\text { diameter of } 365[\mathrm{~mm}]\end{array}$ \\
\hline No. of kilometres driven & $41000 \mathrm{~km}$ \\
\hline Tyres & $\begin{array}{c}\text { GOODYEAR 245/45 } \\
\text { R19 } 102 \mathrm{~V}\end{array}$ \\
\hline
\end{tabular}




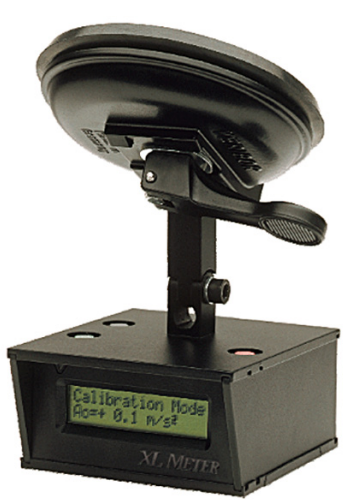

Fig. 3. XL Meter ${ }^{\mathrm{TM}}$ Pro [7]

\section{MEASURING EQUIPMENT}

An XL Meter ${ }^{\mathrm{TM}}$ Pro decelograph and a smartphone were used as the measuring and recording devices during the intensive braking deceleration.

\section{Meter ${ }^{\mathrm{TM}}$ Pro Decelograph}

An XL Meter ${ }^{\mathrm{TM}}$ Pro decelograph was used for measuring (Fig. 3). It is a universal accelero/decelerometer with the alphanumeric LCD display. It serves to measure and evaluate the vehicle acceleration and the state of its service brakes; it is easy to operate as it uses only three buttons placed at the top of the device box $[7,15]$.

XL Meter ${ }^{\mathrm{TM}}$ Pro consists of three main parts: electronics, a vacuum suction cupule and an articulated arm which allows customizable mounting. XL Meter ${ }^{\mathrm{TM}}$ Pro is easy to attach to the desired location on the surface of the vehicle windshield or any other smooth surface and it can be fixed to the surface by turning the lever of the vacuum suction cupule [16]. The electronic system of the device continuously records the values of the output signal voltage during the measurement, with the sampling rate of $200 \mathrm{~Hz}$, i.e. the values are measured and recorded every $5 \mathrm{~ms}[3,4]$. The device records the course of acceleration within a span of 80 seconds from the moment of being turned on. Other technical data are described in Table 2 [18].

The advantage of the XL Meter ${ }^{\mathrm{TM}}$ Pro is that the measured data can be transferred as inputs into further applications (e.g. PC Crash). A decelograph XL Meter ${ }^{\mathrm{TM}}$ Pro is very easy to control and also is a reliable measuring device helping to record and to interpret the braking tests. [X] Provision EHK no. 13 regulates the efficiency of the braking systems. The efficiency of the braking system is defined by the measured braking distance related to the initial velocity of the vehicle, or by the measured average full braking deceleration $[12,15]$. According to the provision EHK no. 13, the accuracy of the average full braking deceleration must be $\pm 3 \%$. The XL Meter ${ }^{\mathrm{TM}}$ Pro measuring device meets the requirements of this provision and is therefore fully appropriate to be used for measuring the braking properties [18].

\section{Smartphone and apps used}

Besides XL Meter ${ }^{\mathrm{TM}}$, the braking characteristics used were also measured with the Samsung Galaxy J3 smartphone and Best Level and Accelerometer Analyzer mobile applications.

Table 2. Basic specifications

\begin{tabular}{|c|c|}
\hline Technical Data & Features \\
\hline 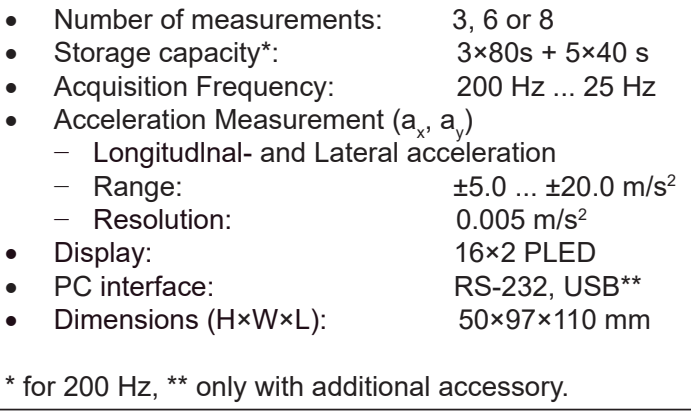 & $\begin{array}{l}\text { - } \text { Measures Longitudinal- and Lateral acceleration } \\
\text { - } \quad \text { Extra fast, strong installation, easy handling } \\
\text { - } \text { Brake pedal input and trigger output } \\
\text { - } \text { On the spot service brake performance evaluation } \\
\text { - } \text { On the spot acceleration performance evaluation Modular } \\
\text { - } \text { system architecture } \\
\text { - } \quad \text { Relectable acceleration direction } \\
\text { - } \quad \text { Optional display language } \\
\text { - } 80 \text { hours continuous operation with one battery-set }\end{array}$ \\
\hline \multicolumn{2}{|c|}{ Applications } \\
\hline $\begin{array}{l}\text { - } \quad \text { Service brake performance evaluation } \\
\text { - } \quad \text { Retarder brake performance evaluation } \\
\text { - } \quad \text { Tram brake performance evaluation } \\
\text { - } \text { Accident reconstruction } \\
\text { - } \quad \text { Vehicle diagnostics measurement }\end{array}$ & $\begin{array}{ll}\text { - } & \text { Substitute for Roli Brake Test Bench } \\
\text { - } & \text { Technical condition survey } \\
\text { - } & \text { Drag racing, tuning } \\
\text { - } & \text { Vehicle dynamics measurement } \\
\text { - } & 0-100 \mathrm{~km} / \mathrm{h}, 0-1 / 4 \text { mile etc. speed-up tests }\end{array}$ \\
\hline
\end{tabular}



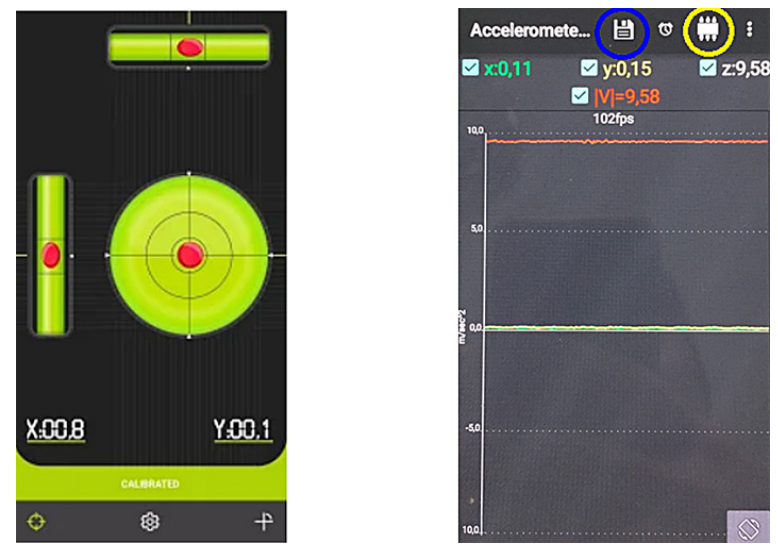

Fig. 4. Best level (left) and Accelerometer Analyzer (right) applications [20]

The Samsung Galaxy J3 smartphone, model type 2016, belongs to the medium category of touch-screen mobile phones. It has five-inch HD display and four CPU cores plus Android 5.1 Lollipop operation system.

The smartphone has the so-called accelerometer with multiple functions. There is a motion sensor that can be used e.g. for flipping the display, for accepting or declining the call, and to control the applications [13].

The motion sensor in the mobile telephone allowed us to use it as the measuring device after downloading the Best Level and Accelerometer Analyzer applications, both being freeware. The Best Level application was used to set up the right position of the device (smartphone), so as to have it vertically aligned against the road (see Fig. 4).

The Accelerometer Analyzer application is designed solely for the devices with the Android operating system. Once installed into the equipment, it helps to record the movement of the device. The Accelerometer Analyzer application is controlled by two buttons. Before starting the very process of measuring, it is inevitable to make

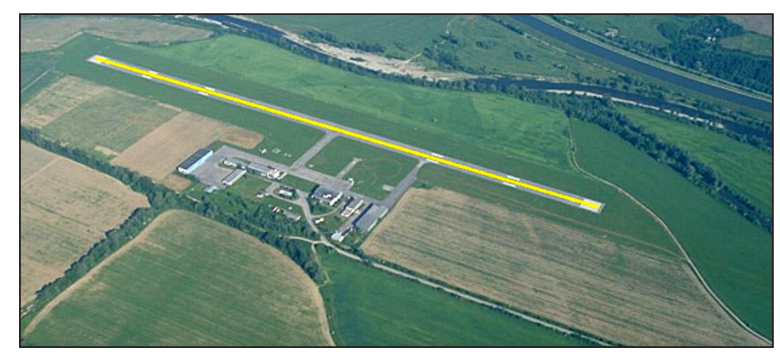

Fig. 5. Measurement place - the runway at the Žilina airport a test of settings of this programme by touching the icon shown in a yellow circle in Fig. 4 [20]. Thereafter, the acceleration or deceleration can be measured. Each measurement is saved in the memory of the smartphone.

\section{THE MEASUREMENT AND THE METHODOLOGY}

The experiment was carried out on September 21, 2018. Because the authors wanted to execute the measurements also under much higher velocity demanding longer route, it took place at the airport in Žilina (in the vicinity of the Horný Hričov village). The outdoor temperature was $11.2^{\circ} \mathrm{C}$, the temperature of the road was $10.8^{\circ} \mathrm{C}$, wind velocity $7 \mathrm{~km} \cdot \mathrm{h}^{-1}$, air humidity $64 \%$. The measurement of the braking properties was carried out on the runway (yellow colour) more than $1000 \mathrm{~m}$ long (see Fig. 5).

The surface of the runway is covered with quality asphalt with estimated adhesion coefficient $0.85-0.90$ (dry surface) and $0.55-0.65$ (wet surface).

The aim of such practical measuring was to define the braking characteristics of the tested Tesla model S electric vehicle on both dry and wet surfaces at different velocities.

Each measurement was repeated twice for the following approximate velocity ranges: $30 \mathrm{~km} \cdot \mathrm{h}^{-1}$, $40 \mathrm{~km} \cdot \mathrm{h}^{-1}, 50 \mathrm{~km} \cdot \mathrm{h}^{-1}, 70 \mathrm{~km} \cdot \mathrm{h}^{-1}, 80 \mathrm{~km} \cdot \mathrm{h}^{-1}, 90$ $\mathrm{km} \cdot \mathrm{h}^{-1}, 100 \mathrm{~km} \cdot \mathrm{h}^{-1}$ and $120 \mathrm{~km} \cdot \mathrm{h}^{-1}$. In total, 16 measurements were performed per each surface.

The authors focused on the specification of the full braking deceleration, braking distance and braking time at the selected velocities.

The measurement methodology was as follows:

1. Heating up the brakes and tyres to the operating temperature.

2. Installation of the XL Meter ${ }^{\mathrm{TM}}$ Pro and Smartphone on the inside the windshield by means of the vacuum suction cupules (see Fig. 6).

3. Calibration of the XL Meter ${ }^{\mathrm{TM}}$ Pro and Smartphone.

4. Acceleration and reaching the specified vehicle velocity.

5. Intensive braking with full braking deceleration of the testing vehicle after reaching the specified velocity.

6. Complete stopping of the testing vehicle.

7. Saving the measured data. 


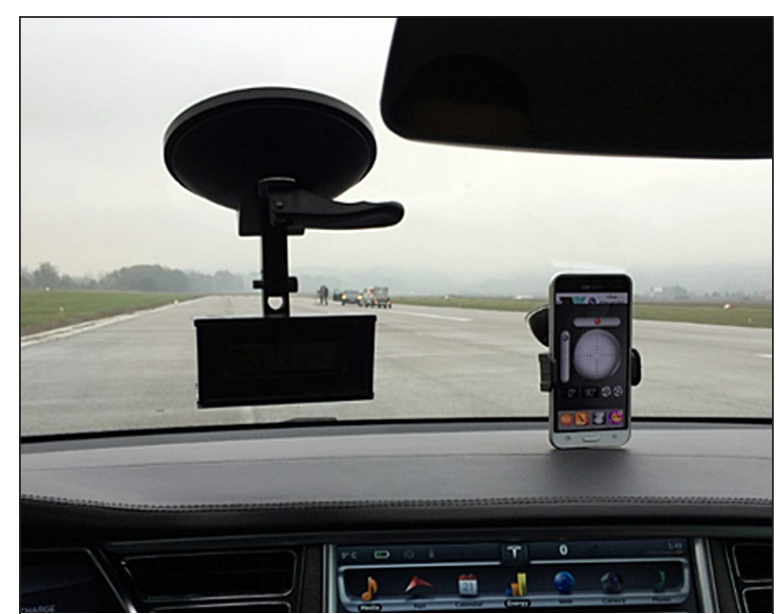

Fig. 6. Installation of the measurement devices

\section{DATA PROCESSING}

Three programmes were used for processing the measured data. The dData obtained by the measuring device XL Meter ${ }^{\mathrm{TM}}$ Pro were processed by the XL Vision ${ }^{\mathrm{TM}}$ and PC Crash 11.0 programmes. In order to process the data obtained by means of the Samsung Galaxy J3 smartphone, the Diagram software was used. The corresponding tables and diagrams were prepared using the MS Excel spreadsheet.

\section{Programmes XL Vision ${ }^{\mathrm{TM}}$ and PC crash 11.0}

This easily accessible computer XL Vision $^{\mathrm{TM}}$ programme provides communication, transfer and processing of the measured data between a PC and the XL Meter ${ }^{\mathrm{TM}}$ Pro device by means of a standard USB cable. XL Vision $^{\mathrm{TM}}$ works under the Microsoft Windows operation system. Data transfer is available after downloading the programme and interconnecting the XL Meter ${ }^{\mathrm{TM}}$ Pro measuring device with the computer $[11,18]$.

All the data obtained by the XL Meter ${ }^{\mathrm{TM}}$ Pro measuring device can be saved and interpreted also later, in the off-line regime. Individual records are saved in the permanent memory and are therefore accessible also if the device is turned off. The memory capacity encompasses eight measurements [11].

The XL Vision software is compatible with several applications used for analysing car accidents, such as Virtual Crash or PC Crash.

The XL Vision ${ }^{\mathrm{TM}}$ software can display and save the measurement values in the form of diagrams showing the process of measuring. These files containing the measured data were saved in the SW XL Vision ${ }^{\mathrm{TM}}$ as the file PC Crash (.asc) [11], so that they could be opened in the SW PC Crash 11.0 allowing to process and to interpret the data with higher accuracy (see Fig. 7 left).

\section{Programme Diagram}

The Diagram programme is a software used to interpret the data recorded by a mobile phone (see Fig. 7 right). Primarily, this is intended to interpret the average value of the vehicle deceleration during hard braking; such value is derived from the acceleration and deceleration values obtained during the start-up and hard braking, having been recorded by the mobile phone, i.e., by the Accelerometer Analyzer application. The programme, however, is useful also when interpreting other driving manoeuvres, such as crosswise shift while changing the traffic lane, etc. [17].
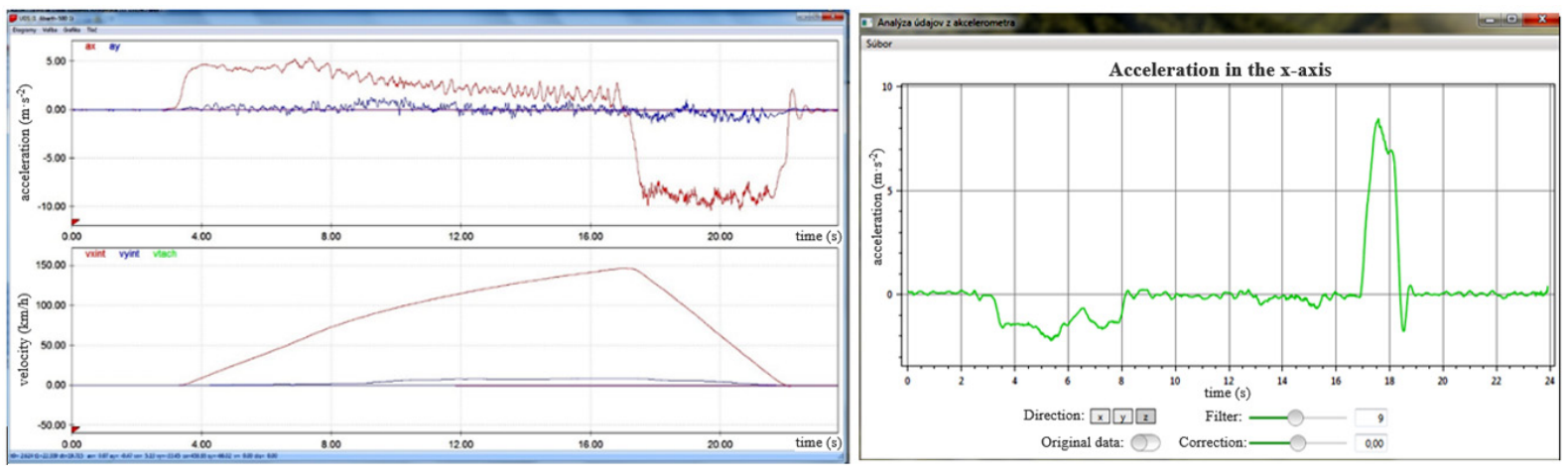

Fig. 7. Demonstration of the braking attributes evaluation in the PC Crash 11.0 (left) and Diagram (right) programmes [17] 
Table 3. Final measured data on the dry road surface for the XL Meter ${ }^{\mathrm{TM}}$ Pro and Smartphone

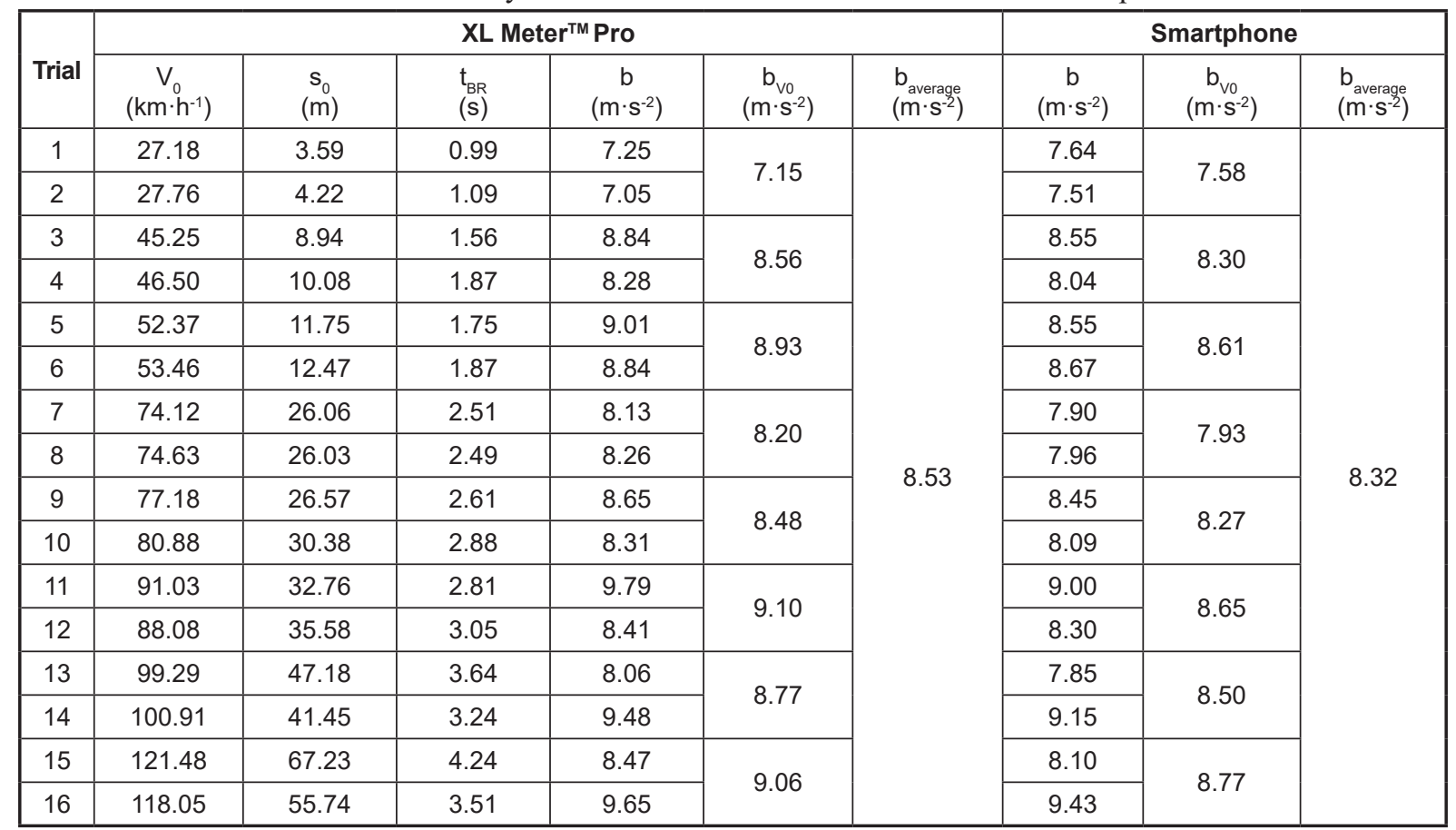

\section{EVALUATION OF THE MEASURED DATA AND THE RESULTS}

The values obtained from the braking characteristics measurement of the Tesla model $\mathrm{S}$ electric vehicle are stated in tables 3 and 4, depending on the road surface. All data were processed and evaluated using the PC - Crash 11.0 and SW Diagram programmes. The tables contain the velocities at the beginning of full braking deceleration $\left(V_{0}\right)$, braking distances $\left(s_{0}\right)$, braking times $\left(t_{B R}\right)$ and the values for full braking deceleration $(b)$. Apart from the data stated above we also added to the table other data, such as average full braking deceleration during individual velocities $\left(b_{\mathrm{v} 0}\right)$ and the total average full braking deceleration $\left(b_{\text {average }}\right)$.

\section{Dry road surface}

Almost all values of full braking deceleration measured with the XL Meter ${ }^{\mathrm{TM}}$ exceed $8 \mathrm{~m} \cdot \mathrm{s}^{-2}$, apart from the velocity of $27 \mathrm{~km} \cdot \mathrm{h}^{-1}$, where the values reached were $7.25 \mathrm{~m} \cdot \mathrm{s}^{-2}$ and $7.05 \mathrm{~m} \cdot \mathrm{s}^{-2}$, which is the lowest value of the full braking deceleration. When evaluating full braking deceleration by means of a smartphone, the values under $8 \mathrm{~m} \cdot \mathrm{s}^{-2}$ were recorded in five measurements.

Table 3 presents the calculated values of the final measured braking characteristics on the dry asphalt. The values of the baverage evaluated by means of XL Meter ${ }^{\mathrm{TM}}$ Pro $\left(8.53 \mathrm{~m} \cdot \mathrm{s}^{-2}\right)$ and a smartphone $\left(8.32 \mathrm{~m} \cdot \mathrm{s}^{-2}\right)$ are almost identical (divergence of $2.46 \%$ ). In almost all cases, the full braking deceleration values measured with the smartphone were slightly lower than those measured by means of the XL MeterTM Pro.

Calculated values:

$-\mathrm{b}_{\max }: 9.79 \mathrm{~m} \cdot \mathrm{s}^{-2}$ (test $11, \mathrm{XL}$ Meter ${ }^{\mathrm{TM}}$ Pro),

- $b_{\max }: 9.43 \mathrm{~m} \cdot \mathrm{s}^{-2}$ (test 16 , Smartphone),

$-\mathrm{b}_{\min }: 7.05 \mathrm{~m} \cdot \mathrm{s}^{-2}$ (test 2, XL Meter ${ }^{\mathrm{TM}}$ Pro),

- $\mathrm{b}_{\text {min }}: 7.51 \mathrm{~m} \cdot \mathrm{s}^{-2}$ (test 2, Smartphone),

- $\mathrm{b}_{\text {average }}: 8.53 \mathrm{~m} \cdot \mathrm{s}^{-2}$ (XL Meter ${ }^{\mathrm{TM}}$ Pro),

- $\mathrm{b}_{\text {average }}: 8.32 \mathrm{~m} \cdot \mathrm{s}^{-2}$ (Smartphone),

- standard deviation of the full braking deceleration: $0.733 \mathrm{~m} \cdot \mathrm{s}^{-2}$ (XL Meter ${ }^{\mathrm{TM}}$ Pro), $0.528 \mathrm{~m} \cdot \mathrm{s}^{-2}$ (Smartphone).

For the final comparison of all measured data, the authors decided to use the dependence of the braking distance on the initial speed. The orange curve in the figure 8 shows the values reached by the vehicle Tesla model $\mathrm{S}$ during the measurements. The curve statistically represents the results measured by the XL Meter ${ }^{\mathrm{TM}}$ Pro. This orange curve is also described by the regression equation. Variable $y$ is equal to the square regression. Variable $R^{2}\left(R^{2}=0.9938\right)$ shows the equation of the regression reliability. The value is very high, which confirms the correctness of the regression type selection. 


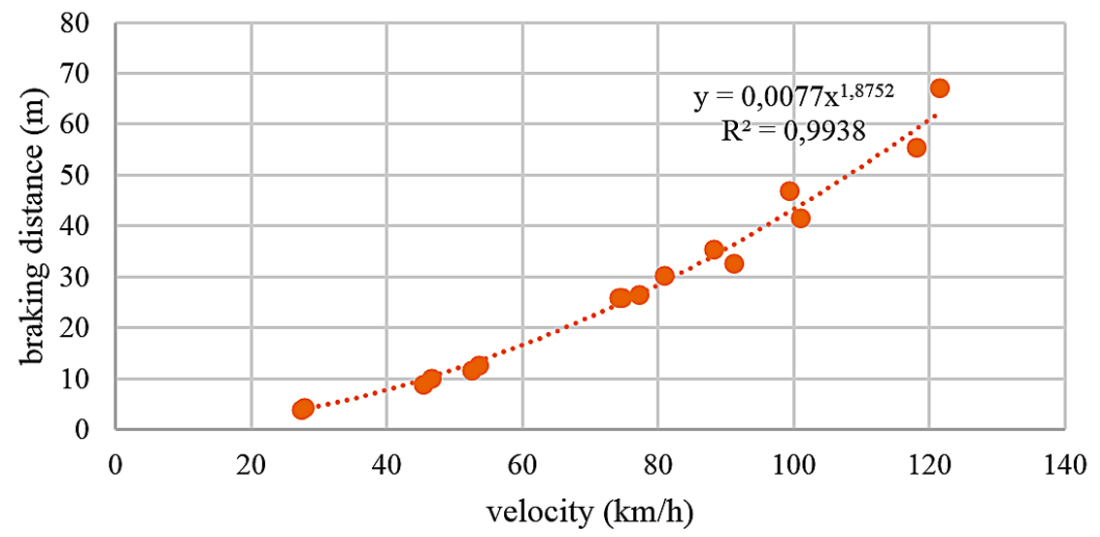

Fig. 8. The dependence of the braking distance on the initial speed of the Tesla model S electric vehicle on the dry surface

\section{Wet road surface}

The evaluation of the values of the full braking deceleration by means of the XL Meter ${ }^{\mathrm{TM}}$ shows the values lower than $8 \mathrm{~m} \cdot \mathrm{s}^{-2}$ for 7 measurements. The evaluation of the full braking deceleration by means of the smartphone shows the values above $8 \mathrm{~m} \cdot \mathrm{s}^{-2}$ for 7 measurements only. The remaining 9 measurements reached the values lower than $8 \mathrm{~m} \cdot \mathrm{s}^{-2}$.

Table 4 presents the calculated values of final measured braking characteristics on the wet asphalt. The values of the $b_{\text {average }}$ evaluated by XL Meter $^{\mathrm{TM}}$ Pro $\left(8.10 \mathrm{~m} \cdot \mathrm{s}^{-2}\right)$ and a smartphone $(7.94$ $\mathrm{m} \cdot \mathrm{s}^{-2}$ ) are, again, nearly identical (divergence of $2.0 \%$ ). Moreover, the values obtained from XL Meter $^{\mathrm{TM}}$ Pro are slightly higher than the values reached from the smartphone.

Calculated values:

$-\mathrm{b}_{\max }: 8.94 \mathrm{~m} \cdot \mathrm{s}^{-2}$ (test 14, XL Meter ${ }^{\mathrm{TM}}$ Pro),

$-\mathrm{b}_{\max }: 8.76 \mathrm{~m} \cdot \mathrm{s}^{-2}$ (test 14 , Smartphone),

$-\mathrm{b}_{\min }: 7.10 \mathrm{~m} \cdot \mathrm{s}^{-2}$ (test 1 , XL Meter ${ }^{\mathrm{TM}}$ Pro),

- $\mathrm{b}_{\min }: 7.06 \mathrm{~m} \cdot \mathrm{s}^{-2}$ (test 7, Smartphone),

- $\mathrm{b}_{\text {average }}: 8.10 \mathrm{~m} \cdot \mathrm{s}^{-2}$ (XL Meter ${ }^{\mathrm{TM}}$ Pro),

- $\mathrm{b}_{\text {average }}: 7.94 \mathrm{~m} \cdot \mathrm{s}^{-2}$ (Smartphone),

- standard deviation of the full braking deceleration: $0.492 \mathrm{~m} \cdot \mathrm{s}^{-2}$ (XL Meter ${ }^{\mathrm{TM}}$ Pro), $0.440 \mathrm{~m} \cdot \mathrm{s}^{-2}$ (Smartphone).

Table 4. Final measured data on the wet road surface for the XL Meter ${ }^{\mathrm{TM}}$ Pro and Smartphone

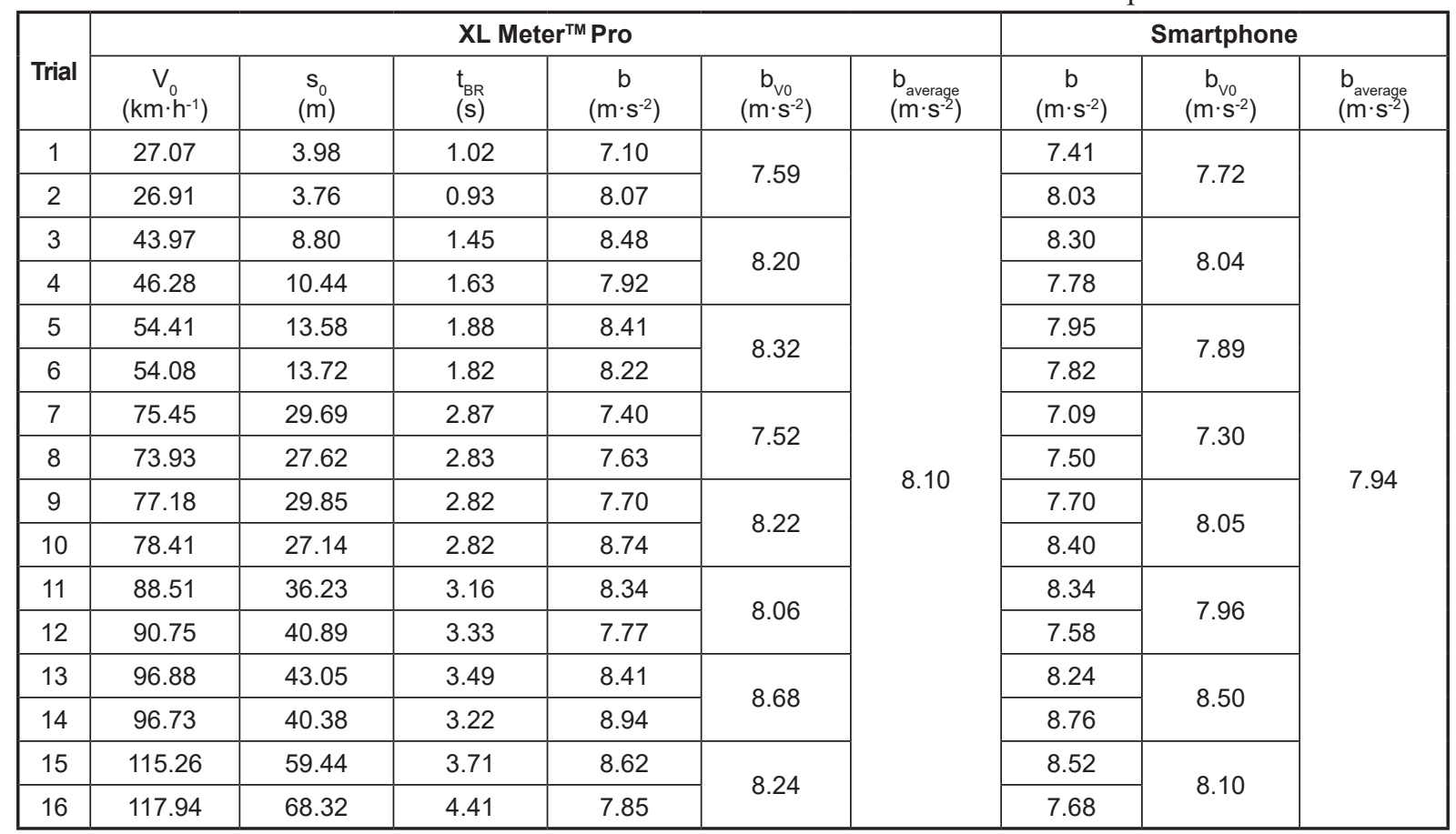




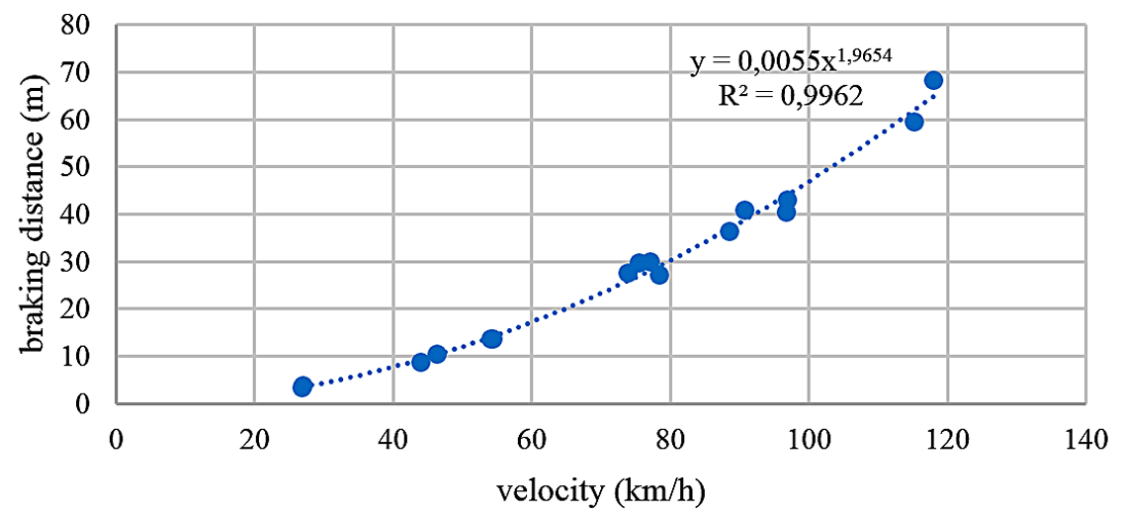

Fig. 9. The dependence of the braking distance on the initial speed of the Tesla model $\mathrm{S}$ electric vehicle on the wet surface

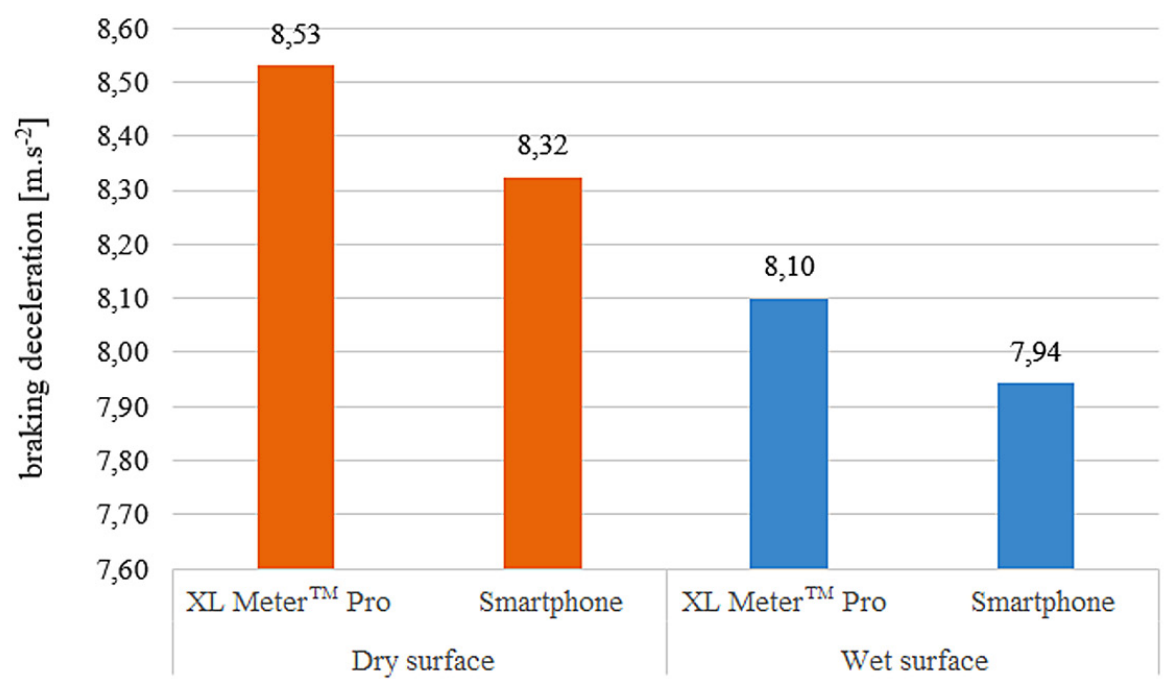

Fig. 10. The results of the braking characteristics of the Tesla model $\mathrm{S}$ electric vehicle on both dry and wet surfaces

On the dry, as well as on the wet surface, the distance grows with growing velocity. The results of the individual measurements on the wet surface are shown by the blue curve in figure 9 . Here, the formula of the regression curve (the square trend) and the reliability value of the variable $R^{2}=0.9962$ can also be observed.

Similarly to the previous value, also this value of the reliability formula approaches 1 , which also in this case confirms the correct choice of the respective regression.

The results reached during the braking in the Tesla model S electric vehicle on both dry and wet surface are shown in the following figure 10. The high accuracy of the results obtained by means of the smartphone can be observed, compared to the XL Meter ${ }^{\mathrm{TM}}$ Pro decelograph. The high values of the full braking deceleration on the wet road surface, compared to the dry road surface, are an interesting feature.

\section{The braking distances comparison with the changed road surface condition}

For the purpose of comparing the braking distances correlation from the initial velocities, such measurements, where the difference among the individual measurements on the dry and wet surfaces was up to $1 \mathrm{~km} \cdot \mathrm{h}^{-1}$, were selected. This difference was considered because it is not possible to reach a completely identical initial velocities for such demanding practical measurements.

The following table 5 comprises the data, which complied to the condition set and it was possible to compare them. It contains the velocities 
Table 5. The braking characteristics comparison on the dry and wet road surface

\begin{tabular}{|c|c|c|c|c|c|c|}
\hline \multicolumn{2}{|c|}{ Dry road surface } & \multicolumn{2}{c|}{ Wet road surface } & \multicolumn{3}{c|}{ Comparison } \\
\hline $\begin{array}{c}\mathrm{V}_{0} \\
\left(\mathrm{~km} \cdot \mathrm{h}^{-1}\right)\end{array}$ & $\begin{array}{c}\mathrm{s}_{0} \\
(\mathrm{~m})\end{array}$ & $\begin{array}{c}\mathrm{V}_{0} \\
\left(\mathrm{~km} \cdot \mathrm{h}^{-1}\right)\end{array}$ & $\begin{array}{c}\mathrm{s}_{0} \\
(\mathrm{~m})\end{array}$ & $\begin{array}{c}\text { Difference } \\
\left(\mathrm{km} \cdot \mathrm{h}^{-1}\right)\end{array}$ & $\begin{array}{c}\text { Braking distance } \\
\text { difference }(\mathrm{m})\end{array}$ & $\begin{array}{c}\text { Braking distance } \\
\text { difference }(\%)\end{array}$ \\
\hline 27.18 & 3.59 & 26.91 & 3.76 & 0.27 & 0.17 & 4.52 \\
\hline 46.50 & 10.08 & 46.28 & 10.44 & 0.22 & 0.36 & 3.45 \\
\hline 53.46 & 12.47 & 54.08 & 13.72 & 0.62 & 1.25 & 9.11 \\
\hline 74.12 & 26.06 & 73.93 & 27.62 & 0.19 & 1.56 & 5.65 \\
\hline 74.63 & 26.03 & 75.45 & 29.69 & 0.82 & 3.66 & 12.33 \\
\hline 77.18 & 26.57 & 77.18 & 29.85 & 0.00 & 3.28 & 10.99 \\
\hline 88.08 & 35.58 & 88.51 & 36.23 & 0.43 & 0.65 & 1.79 \\
\hline 91.03 & 32.76 & 90.75 & 40.89 & 0.28 & 8.13 & 19.88 \\
\hline 118.05 & 55.74 & 117.94 & 68.32 & 0.11 & 12.58 & 18.41 \\
\hline
\end{tabular}

data at the beginning of full braking deceleration $\left(V_{0}\right)$, braking distances $\left(s_{0}\right)$ and their differences. Table 5 also shows the braking distances differences on the dry and wet road surface, additionally provided in percentage.

The part of the comparison of the braking distances (Table 5) of the vehicle Tesla model S on the dry and the wet surface, for the similar velocities, is also the graphical view (Fig. 11), where the comparison of the individual braking distances on both surfaces is better visible. The differences in the braking distances are clearly pointed out in blue colour (prolongations).

The minimum percentage growth of the braking distance on the dry and wet road surface was recorded at the velocity of $88 \mathrm{~km} \cdot \mathrm{h}^{-1}$, meaning $1.79 \%$ (prolongation of braking distance by $0.65 \mathrm{~m}$ ). The highest percentage growth of the braking distance was recorded at the velocity of $91 \mathrm{~km} \cdot \mathrm{h}^{-1}$, precisely $19.88 \%$ (prolongation of braking distance by $8.13 \mathrm{~m}$ ). The median value of the prolonged braking distance between the dry and the wet surface was $9.11 \%$.

\section{CONCLUSION}

An essential contribution of this research is mainly the performance of the practical measurement related to the braking characteristics of the Tesla model $\mathrm{S}$ electric vehicle, on the different road surfaces and from the selected different initial velocities.

The authors focused on the braking distance definition and the full braking deceleration. This is an essential indicator governing the braking distance. This input is fundamental for the experts when carrying out the forensic reports. The full braking deceleration value is the core entry value for the traffic accidents analysis.

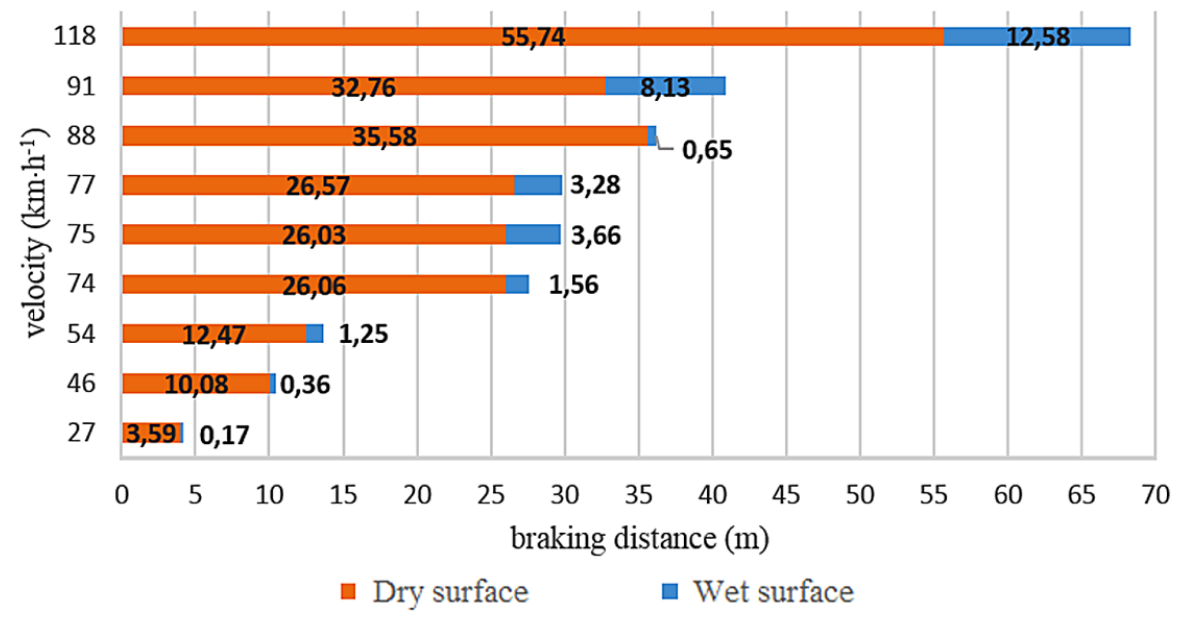

Fig. 11. The comparison of the braking distances of the Tesla electric vehicle on the dry and wet road surface 
The results show that the Tesla model $\mathrm{S}$ electric vehicle has considerably high full deceleration values on the wet surface, compared to the dry surface. All braking distances comparisons on both dry and wet surfaces show that the braking distance on the wet surface was always noticeably longer than the braking distance on the dry surface (considering our criteria that the difference among the individual velocities was up to $1 \mathrm{~km} \cdot \mathrm{h}^{-1}$.

On the basis of the measurement results comparison it can be stated that the results obtained by means of the smartphone are very similar to those obtained by the XL Meter ${ }^{\text {TM }}$ Pro decelograph (with the tolerance of $2-2.5 \%$, depending on the road surface). It can be concluded that the measurement processed by the smartphone is a fully functional alternative to the XL Meter ${ }^{\mathrm{TM}}$ Pro decelograph.

\section{Acknowledgement}

This work was supported in part by the Grant VEGA no. 1/0436/18 - Externalities in road transport, an origin, causes and economic impacts of transport measures.

\section{REFERENCES}

1. Hockicko P. and Trpišová B. Are students' conceptions about automobile braking distances correct? Proc. of 41st SEFI annual conference, Leuven, Belgium 2013, 1-8.

2. Bahrami S., Nourinejad M., Amirjamshidi G. and Roorda, M. J. The Plugin Hybrid Electric Vehicle routing problem: A power-management strategy model. Transportation research part c-emerging technologies, 111, 2020, 318-333.

3. Skrucany T., Synak F. and Semanova S. Influence of the braking system that is contrary to legislation on breaking characteristics of passenger car. Transport technic and technology, 14(1), 2018, 1-5.

4. Kalasova A. and Kupculjakova J. The future in the telematics applications as support for increased safety. Transport Problems, 7(1), 2012, 103-109.

5. Kubasakova I., Kubanova J. and Poliakova B. Modelling of Opened System in the Road Freight Transport and its Impact on the System Characteristics. Proc. of 19th International Scientific Conference on Transport Means. Kaunas, Lithuania 2015, 405-409.

6. Li. W, Cao C., Zhou W. and Gao L. Influences of initial braking velocity and passenger capacity on Mean Fully Developed Deceleration. Mechanical engineering, materials and energy II, Book Series: Applied Mechanics and Materials, Volume: 281, 2013, 201.
7. Ondrus J. and Kolla E. The impact of ABS system on the braking characteristics of the specified motorcycle on the dry road surface. Proc. of Scientific Conference on Automotive Vehicles and Combustion Engines KONMOT 2018. Cracow, Poland 2018, 1-10.

8. Vrabel J., Jagelcak J., Zamecnik J. and Caban J. Influence of Emergency Braking on Changes of the Axle Load of Vehicles Transporting Solid Bulk Substrates. Transbaltica 2017: Transportation science and technology, Book Series: Procedia Engineering, Volume: 187, 2017, 89-99.

9. Kapusta J. and Kalasova, A. Motor Vehicle Safety Technologies in Relation to the Accident Rates. Tools of transport telematics, Book Series: Communications in Computer and Information Science, Volume: 531, 2015, 172-179.

10. Majercak J., Kudlac S. and Panak M. Sustainable and Economically Efficient Five-point Supply Chain Management. Proc. of 20th International Scientific Conference on Transport Means. Juodkrante, Lithuania 2016, 65-70.

11. Ondrus J., Vrabel J. and Kolla E. The influence of the vehicle weight on the selected vehicle braking characteristics. Proc. of 22nd International Scientific on Conference Transport Means 2018, Trakai, Lithuania 2018, 384-390.

12. Skrucany T., Sarkan B., Figlus T., Synak F. and Vrabel J. Measuring of noise emitted by moving vehicles. Dynamics of civil engineering and transport structures and wind engineering (Dyn-wind'2017), Book Series: MATEC Web of Conferences, Volume: 107, 2017, Article Number: UNSP 00072.

13. Hockicko P., Kristak L. and Nemec M. Development of students' conceptual thinking by means of video analysis and interactive simulations at technical universities. European journal of engineering education, (40)2, 2015, 145-166.

14. Sarkan B., Stopka O., Gnap J. and Caban, J. Investigation of Exhaust Emissions of Vehicles with the Spark Ignition Engine within Emission Control. Transbaltica 2017: Transportation science and technology, Book Series: Procedia Engineering Volume: 187, 2017, 775-782.

15. Skrucany T., Vrabel J. and Kazimir. P. The influence of the cargo weight and its position on the braking characteristics of light commercial vehicles. Open engineering, (10)1, 2020, 154-165.

16. Rievaj V., Vrabel J., Synak F. and Bartuska L. The effects of vehicle load on driving characteristics. Advances in Science and Technology-Research Journal, (12)1, 2018, 142-149.

17. SW PC Crash 11.0., SW Diagram.

18. http://www.inventure.hu/xl_meter_en.

19. https://www.tesla.com//models.

20. Mobile applications Best level, Accelerometer Analyzer. 